\title{
Waste Rubber Tires: A Partial Replacement for Coarse Aggregate in Concrete Floor Tile Production
}

\author{
Gemeda Etefa ${ }^{1}$, Alemu Mosisa ${ }^{2}$ \\ ${ }^{1}$ Department of Construction Technology and Management, Wollega University, Nekemte, Ethiopia \\ ${ }^{2}$ Department of Civil Engineering, Jimma University, Jimma, Ethiopia
}

Email address:

gemedaete@gmail(G. Etefa),amosisa@gmail.com (A. Mosisa)

\section{To cite this article:}

Gemeda Etefa, Alemu Mosisa. Waste Rubber Tires: A Partial Replacement for Coarse Aggregate in Concrete Floor Tile Production. American Journal of Civil Engineering. Vol. 8, No. 3, 2020, pp. 57-63. doi: 10.11648/j.ajce.20200803.12

Received: July 4, 2019; Accepted: August 7, 2019; Published: June 8, 2020

\begin{abstract}
Concrete tile is one of the most used construction materials in the world. Cement and aggregate, which are the most important constituents used in concrete tile production, they are the vital materials needed for the construction industry. This led to a continuous and increasing demand of natural materials used for their production. Parallel to the need for the utilization of the natural resources emerges a growing concern for protecting the environment and a need to preserve natural resources (such as aggregate) by using alternative materials which are recycled or waste materials. In this research, a study was carried out on the use of used rubber tires as a partial replacement for coarse aggregates in concrete tile production using locally available waste tires. A review of relevant literatures was done to study previous works in the subject matter. The research was carried out by conducting tests on the raw materials to determine their properties and suitability for the experiment. Concrete mix designs are prepared using the DOE method and a total of 12 mixes were prepared consisting of two concrete grades $(\mathrm{C} 25$ and $\mathrm{C} 30)$. The specimens were produced with percentage replacements of the coarse aggregate by 10, 20, 30, 40 and 50\% of rubber aggregate with and without supper plasticizer (admixture). Moreover, a control mix with no replacement of the coarse aggregate was produced to make a comparative analysis. The prepared samples consist of concrete cubes, cylinders and beams. Laboratory tests were carried out on the prepared concrete samples. The lists of tests conducted are; material property, slump, unit weight, compressive strength, splitting tensile strength and flexural strength tests. The data collection was mainly based on the tests conducted on the prepared specimens in the laboratory. The test results were compared with the respective conventional concrete properties and show that there is a reduction in compressive strength of the concrete due to the inclusion of rubber aggregates. This is improved by using admixture to some extent, but lower density and enhanced ductility are the same, and there was a slight increase in flexural strength without admixture. The overall results show that it is possible to use recycled rubber tires in concrete tile production as a partial replacement for coarse aggregates. Nevertheless, the percentage of replacement should be limited to $10 \%$.
\end{abstract}

Keywords: Waste Rubber, Concrete Tiles, Unit Weight, Compressive Strength, Flexural Strength

\section{Introduction}

Looking at a different matter, the function of a house today is not only for shelter from rain and sun, but a simple house can be a clean, healthy and beautiful place. Also the sidewalk here in our country needs treatment to make the road side attractive and long life. It's evident that a clean and aesthetically pleasing space can be achieved in yards and parking areas by applying concrete floor tiles. Floor tiles can be used for the sidewalk, around houses and office buildings. The main Function of this material is to cover the floor in a long lasting and clean way. Materials used to produce concrete floor tile are cement, sand, aggregate, water and pigments [1].

Aggregate, which are the most important constituents used in concrete tile production, is the vital material needed for the construction industry. This inevitably led to a continuous and increasing demand of natural materials used for their production. Parallel to the need for the utilization of the natural resources emerges a growing concern for protecting the environment and a need to preserve natural resources, such as aggregate, by using alternative materials that are 
either recycled or discarded as a waste [1].

Concrete tile strength is greatly affected by the properties of its constituents and the mix design parameters. Because aggregates represent the major constituent of the bulk of a concrete tile mixture, its physical properties affect the engineering properties of the final product. An aggregate has been customarily treated as inert filler in concrete. However, due to the increasing awareness of the role played by aggregates in determining many important properties of concrete, the traditional view of the aggregate as inert filler is being seriously questioned. Aggregate was originally viewed as a material dispersed throughout the cement paste largely for economic reasons. It is possible, however, to take an opposite view and to look at aggregate as a construction material connected into a cohesive whole by means of the cement paste. In fact aggregate is not truly inert and its physical, thermal, and sometimes chemical properties influence the performance of concrete tile [2].

Aggregate is cheaper than cement and it is, therefore, economical to put into the mix much of the former and as little of the latter as possible. Nevertheless, the economy is not the only reason for using aggregate: it confers considerable technical advantages of concrete tile, which has a higher volume stability and better durability than hydrated cement paste alone [2].

The goal of sustainability is that life on the planet can be sustained for the foreseeable future and there are three components of sustainability: environment, economy, and society. To meet its goal, sustainable development must ensure that these three components remain healthy and balanced. Furthermore, it must do so simultaneously and throughout the entire planet, both now and in the future. At the moment, the environment is probably the most important component and an engineer or architect uses sustainability to mean having no net negative impact on the environment. Among the many threats that affect the environment are the wastes which are generated in the production process or discarded after a specific material ends its lifetime or the intended use. The wastages are divided as solid waste, liquid waste and gaseous wastes. There are many disposal ways for liquid and gaseous waste materials. Some solid waste materials such as plastic bottles, papers, steel, etc. Can be recycled without affecting the environment. However, studies on how to dispose some solid wastes such as waste tires in the most beneficial ways are not yet fully exhausted [1].

A tire is a thermoset material that contains cross-linked molecules of sulphur and other chemicals. The process of mixing rubber with other chemicals to form this thermoset material is commonly known as vulcanization. This makes post-consumer tires very stable and nearly impossible to degrade under ambient conditions. Consequently, it has resulted in a growing disposal problem that has led to changes in legislation and significant researches worldwide [4]. On the other hand, disposal of the waste tires all around the world is becoming higher and higher through time. This keeps on increasing every year with the number of vehicles, as do the future problems relating to the crucial environmental issues [1].

The increasing piles of waste tires will create, the accumulation of used tires at landfill sites and presents the threat of uncontrolled fires, producing a complex mixture of chemicals harming the environment and contaminating soil and vegetation. It was estimated that in the UK alone, 37 million car and truck tires are being discarded annually and this number is set to increase. This is considered as one of the major environmental challenges the World is facing because waste rubber is not easily biodegradable even after a long period of landfill treatment. One of the solutions suggested was the use of tire rubber as partial replacement of coarse aggregate in cement-based materials [1].

If the tire is burned, the toxic product from the tire will damage the environment and thus creating air pollution. Since it is not a biodegradable material, this may affect the fertility of the soil and vegetation. Sometimes it may produce uncontrolled fire. Similarly, the other challenge to the human society is in the form of carbon dioxide emission and green house emission. These emissions are considered as highly threatening wastes to the universe [1].

Since 1990, it has been the policy of the State of Arizona that the recycling and reuse of waste tires are given the highest priority. The Arizona Department of Transportation (ADOT) has long supported the use of recycled waste tire rubber in asphalt rubber hot mix. A cooperative work between ADOT and Arizona State University (ASU) was conducted to extend the use of crumb rubber in Portland cement concrete mixes. The intent was to use such mixes on urban development related projects. A list of feasible projects were identified. Examples are roadways or road intersections, sidewalks, recreational courts and pathways, and wheelchair ramps for better skid resistance. This collaboration has also expanded to include members from industry associations, concrete suppliers and consultants. Several crumb rubber in concrete test sections were built throughout the state of Arizona and are being monitored for performance [3].

Hence, all the above studies suggest that there is a strong need to use waste materials in concrete tile production and specifically waste tires should be used in an environmental friendly way. For this, concrete tile production can be considered as a very realistic and convenient area of application [4]. The present study focuses on the evaluation of the maximum replacement of natural aggregate of cut waste rubber tires in the production of concrete floor tiles.

\section{Materials and Methodology}

This study was based on materials collection, laboratory tests, and to determine optimum rubber combined as a partial replacement of natural coarse aggregate in the concrete tile production. The materials were waste rubber tire, course aggregate, sand cement. Waste tires from Horizon Addis Tire and manually catted in small pieces $(20 \mathrm{~mm})$. 
Table 1. Mix Proportioning for $1 \mathrm{~m}^{3}$ of Concrete.

\begin{tabular}{|c|c|c|c|c|c|c|}
\hline Type & Grade & Cement $\left(\mathrm{Kg} / \mathrm{m}^{3}\right)$ & Water $\left(\mathrm{Kg} / \mathbf{~ m}^{3}\right)$ & $\begin{array}{l}\text { Fine aggregate. } \\
\left(\mathrm{Kg} / \mathbf{~ m}^{3}\right)\end{array}$ & $\begin{array}{l}\text { Coarse aggregate. } \\
\left(\mathrm{Kg} / \mathrm{m}^{3}\right)\end{array}$ & Rubber aggregate. $\left(\mathrm{Kg} / \mathrm{m}^{3}\right)$ \\
\hline Control (1) & $\mathrm{C}-25$ & 295 & 180 & 666.0 & 1294.0 & 0.00 \\
\hline Mix X2 & C-25 & 295 & 180 & 666.0 & 1164.6 & 55.30 \\
\hline Mix X3 & $\mathrm{C}-25$ & 295 & 180 & 666.0 & 1035.2 & 110.60 \\
\hline Mix X4 & $\mathrm{C}-25$ & 295 & 180 & 666.0 & 905.8 & 165.90 \\
\hline Mix X5 & C-25 & 295 & 180 & 666.0 & 776.4 & 221.20 \\
\hline Mix X6 & $\mathrm{C}-25$ & 295 & 180 & 666.0 & 647 & 276.50 \\
\hline Mix Y2 & $\mathrm{C}-30$ & 327 & 180 & 656.0 & 1144.8 & 54.36 \\
\hline $\operatorname{mix} Y 3$ & C-30 & 327 & 180 & 656.0 & 1017.6 & 108.72 \\
\hline $\operatorname{mix} Y 4$ & C-30 & 327 & 180 & 656.0 & 890.4 & 163.08 \\
\hline mixY5 & C-30 & 327 & 180 & 656.0 & 763.2 & 217.44 \\
\hline $\operatorname{mix} Y 6$ & C-30 & 327 & 180 & 656.0 & 636 & 271.80 \\
\hline
\end{tabular}

Table 2. Mix Proportions for $0.062 \mathrm{~m}^{3}$ of concrete.

\begin{tabular}{|c|c|c|c|c|c|c|}
\hline Type & Grade & Cement $\left(\mathrm{Kg} / \mathrm{m}^{3}\right)$ & Water $\left(\mathrm{Kg} / \mathbf{m}^{3}\right)$ & $\begin{array}{l}\text { Fine aggregate. } \\
\left(\mathrm{Kg} / \mathrm{m}^{3}\right)\end{array}$ & $\begin{array}{l}\text { Coarse aggregate. }(\mathrm{Kg} / \\
\left.\mathrm{m}^{3}\right)\end{array}$ & $\begin{array}{l}\text { Rubber aggregate. } \\
\left(\mathrm{Kg} / \mathrm{m}^{3}\right)\end{array}$ \\
\hline Control (1) & $\mathrm{C}-25$ & 18.29 & 11.16 & 41.29 & 80.23 & 0.00 \\
\hline Mix X2 & $\mathrm{C}-25$ & 18.29 & 11.16 & 41.29 & 72.21 & 3.30 \\
\hline Mix X3 & $\mathrm{C}-25$ & 18.29 & 11.16 & 41.29 & 64.18 & 6.60 \\
\hline Mix X4 & $\mathrm{C}-25$ & 18.29 & 11.16 & 41.29 & 56.16 & 9.90 \\
\hline Mix X5 & $\mathrm{C}-25$ & 18.29 & 11.16 & 41.29 & 48.14 & 13.20 \\
\hline Mix X6 & $\mathrm{C}-25$ & 18.29 & 11.16 & 41.29 & 40.12 & 16.50 \\
\hline Control (1) & C-30 & 20.27 & 11.16 & 40.67 & 78.86 & 0.00 \\
\hline Mix Y2 & $\mathrm{C}-30$ & 20.27 & 11.16 & 40.67 & 70.97 & 3.37 \\
\hline $\operatorname{mix} Y 3$ & C-30 & 20.27 & 11.16 & 40.67 & 63.09 & 6.74 \\
\hline $\operatorname{mix} Y 4$ & $\mathrm{C}-30$ & 20.27 & 11.16 & 40.67 & 55.2 & 10.11 \\
\hline $\operatorname{mix} Y 5$ & C-30 & 20.27 & 11.16 & 40.67 & 47.32 & 13.48 \\
\hline $\operatorname{mix} Y 6$ & $\mathrm{C}-30$ & 20.27 & 11.16 & 40.67 & 39.43 & 16.85 \\
\hline
\end{tabular}

The required concrete volume to be produced in each of the 12 test arrangements was $0.062 \mathrm{~m}^{3}$. Prior to the mixing process, all the required ingredients to produce the overall volume of concrete planned were prepared in the laboratory.

\section{Result and Discussion}

The strengths of concrete specimens were determined after the $7^{\text {th }}$ and $28^{\text {th }}$ days of standard curing. For rubberized concrete, the results show that the addition of rubber aggregate resulted in a significant reduction in concrete compressive strength compared with the control concrete. This reduction increased with increasing percentage of rubber aggregate. Losses in compressive strength of $12.98 \%$
(XA2) and $13.97 \%$ (YA2) were observed when $10 \%$ of the coarse aggregate was replaced by an equivalent volume of rubber aggregate. Losses of 24.64\% (XA3) and 26.21\% (YA3) were observed when $20 \%$ of coarse aggregate was replaced by rubber aggregate. The observed losses of strength when $30 \%$ of the coarse aggregate was replaced by rubber aggregate were $34.68 \%$ (XA4) and $37.41 \%$ (YA4). Losses of 51.23 (XA5) and $54.18 \%$ (YA5) were observed when $40 \%$ of coarse aggregate was replaced by rubber aggregate. Finally, losses of strength $63.68 \%$ (XA6) and $62.42 \%$ (YA6) were observed for rubberized concrete containing $50 \%$ by volume of rubber aggregate replacement. Table 3 below shows the results of the $7^{\text {th }}$ and $28^{\text {th }}$ day compressive strength tests.

Table 3. Compressive strength tests results.

\begin{tabular}{llllllll}
\hline \multirow{2}{*}{ No. } & Samples & Grade & \multirow{2}{*}{ \%rubber } & \multicolumn{2}{c}{ Comp. str. (MPa) } & \multicolumn{2}{c}{ \%str. Loss } \\
\cline { 5 - 8 } & & 7 days & 28 days & 7days & 28days \\
\hline 1 & XA1 & C-25 & 0 & 29.20 & 40.91 & 0.00 & 0.00 \\
2 & XA2 & C-25 & 10 & 24.30 & 35.60 & 16.78 & 12.98 \\
3 & XA3 & C-25 & 20 & 23.24 & 30.83 & 20.41 & 24.64 \\
4 & XA4 & C-25 & 30 & 17.75 & 26.72 & 39.21 & 34.68 \\
5 & XA5 & C-25 & 40 & 15.21 & 20.96 & 47.91 & 51.23 \\
6 & XA6 & C-25 & 50 & 12.34 & 14.86 & 57.74 & 63.68 \\
7 & YA1 & C-30 & 0 & 36.01 & 49.26 & 0.00 & 0.00 \\
8 & YA2 & C-30 & 10 & 32.04 & 42.38 & 11.02 & 13.97 \\
9 & YA3 & C-30 & 20 & 22.45 & 36.35 & 37.71 & 26.21 \\
10 & YA4 & C-30 & 30 & 18.82 & 30.83 & 47.74 & 37.41 \\
11 & YA5 & C-30 & 40 & 15.10 & 22.57 & 58.06 & 54.18 \\
12 & YA6 & C-30 & 50 & 14.07 & 18.51 & 61.01 & 62.42 \\
\hline
\end{tabular}


Figures 1 and 2 below illustrates the trend of strength development in the different concrete Specimens prepared and the comparison of the strength achieved in contrast with the control concrete.

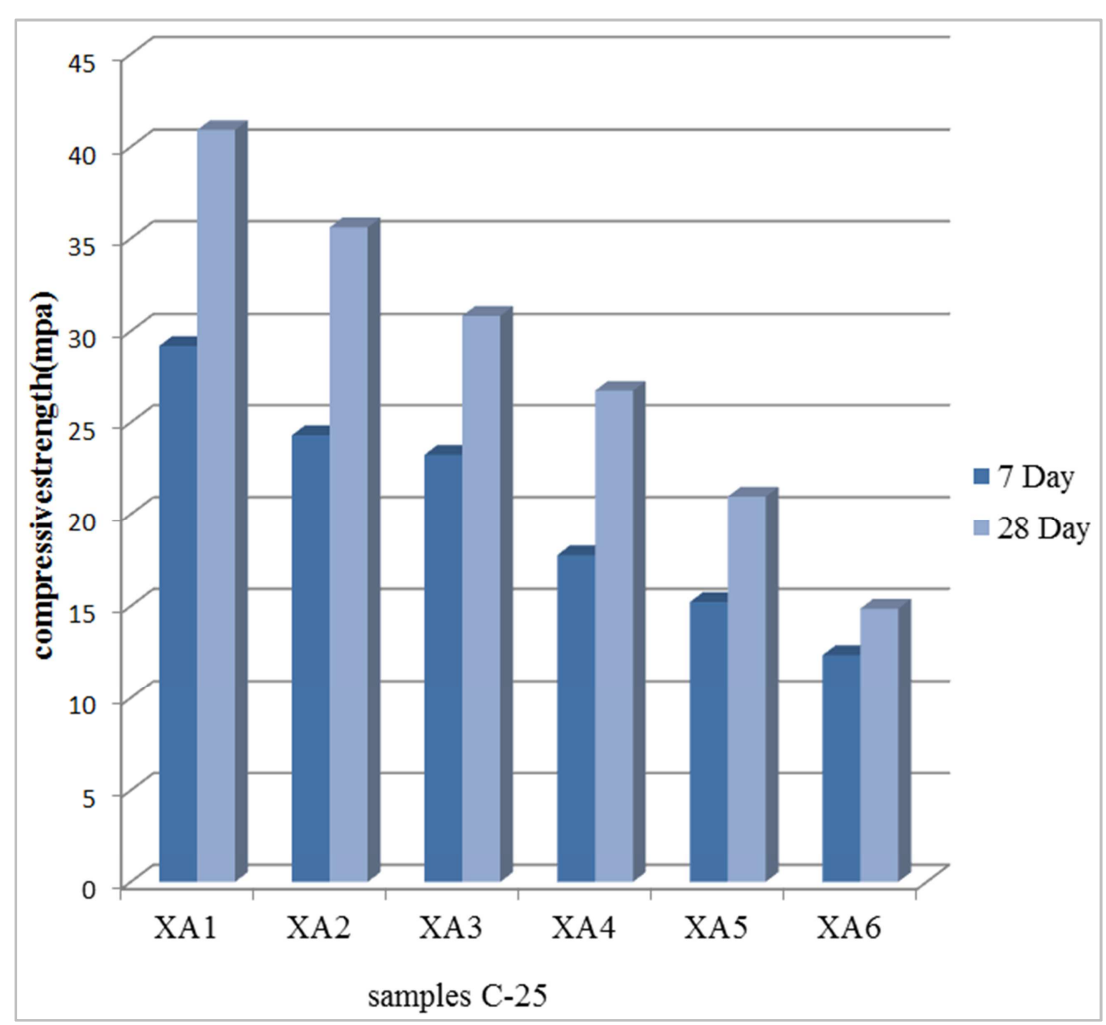

Figure 1. Compressive strength comparisons of samples. (C-25).

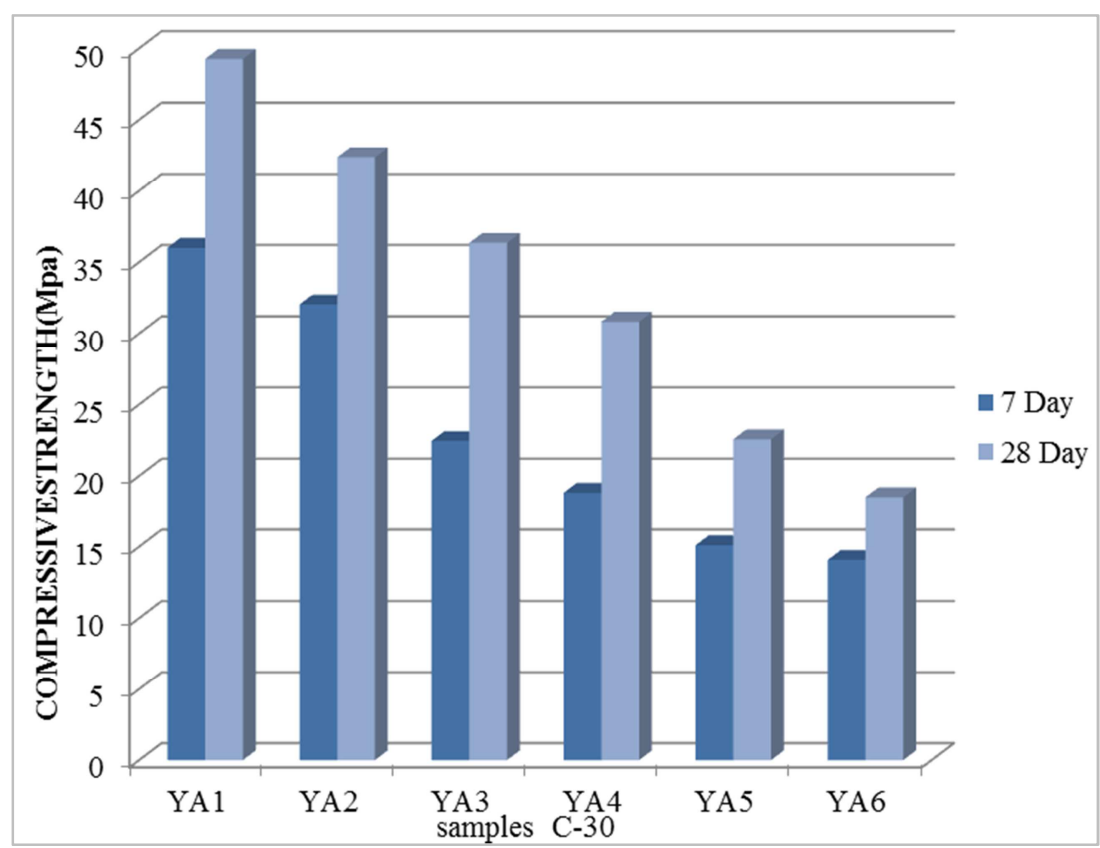

Figure 2. Compressive strength comparisons of samples. (C-30).

There was a reduction of compressive strength as percentage of rubber increased. The reason for the compressive strength reductions could be attributed both to a reduction of the quantity of the solid load carrying material and to the lack of adhesion at the surfaces of the rubber aggregate. Soft rubber particles behave as voids in the concrete matrix. Considering the very different mechanical properties of mineral aggregates and rubber aggregates, mineral aggregates usually has high crushing strength and they are relatively incompressible, whereas rubber aggregates 
are ductile, compressible and resilient. Rubber has a very low modulus of elasticity of about 7MPa and a Poisson's ratio of 0.5 [12]. Therefore, rubbers aggregates tend to behave like weak inclusions or voids in the concrete, resulting in a reduction in compressive strength. It is well known that the presence of voids in concrete greatly reduces its strength. The existence of $5 \%$ of voids can lower strength by as much as $30 \%$ and even $2 \%$ voids can result in a drop of strength of more than $10 \%$, this result is conformed to this literature values [2].

During pure bending, the member resisting the action is subject to internal actions or stresses (shear, tensile and compressive). For a bending force applied downward on a member supported simply at its two ends, fibers above the neutral axis are, generally, subjected to compressive stresses and those below the neutral axis to tensile stresses. For this load and support system, portions of the member near the supports are subjected to relatively higher shear stresses than tensile stresses. In this test, the concrete member to be tested is supported at its ends and loaded at its interior locations by a gradually increasing load to fail. The failure load (loading value at which the concrete cracks heavily) is then recorded and used to determine the tensile stress at which the member failed, i.e. Its tensile strength [29].

The prepared beam samples were tested after 28 days of standard curing and the results of flexural strength tests for the control concretes and the rubberized concretes are summarized below in Table 4.

Table 4. Flexural strength tests results.

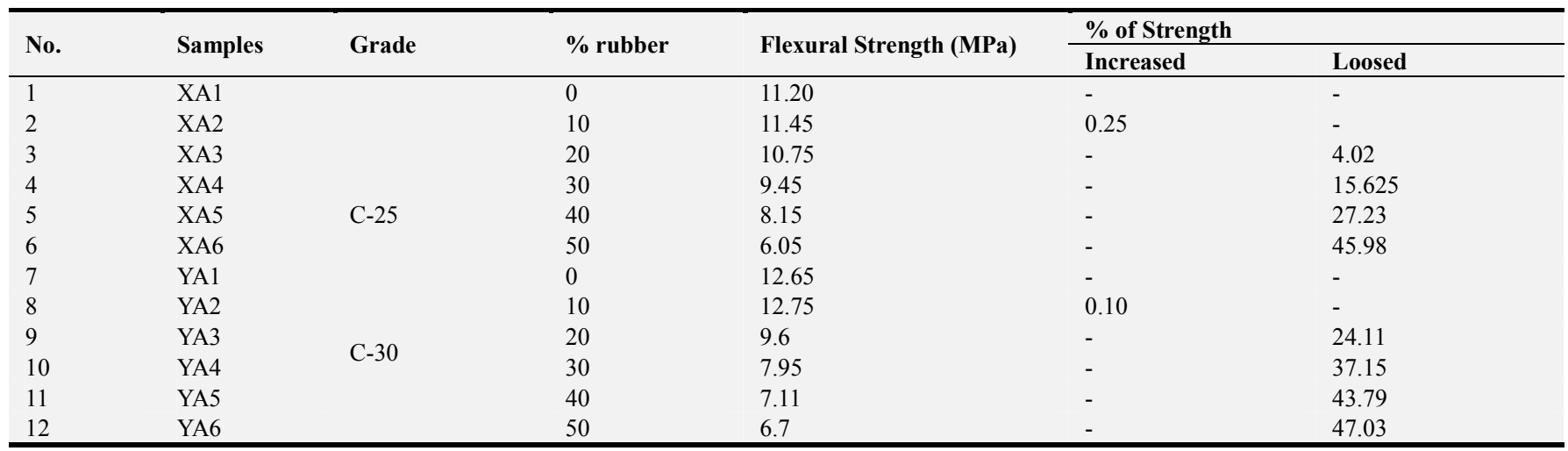

There was an increased flexural strength only when ten percent $(10 \%)$ of the coarse aggregate was replaced by rubber aggregate, but reduction of flexural strength observed when more than ten percent $(10 \%)$ of coarse aggregate replaced by rubber aggregate compared with control. This shows that improvements in flexural strength are limited to a relatively small amount of rubber aggregate contents.

As the test result shows there was an advantage of increasing in flexural strength to some extent replacing coarse aggregate by $10 \%$ of rubber aggregate only. It can be concluded that as the amount of rubber content increases, by more than $10 \%$ the reduction in the flexural strength also increases.

\section{Conclusion}

As the suitability of the materials is checked and adjusted there was no constraint with the materials used for this research. The following conclusion has drawn by considering the test result and discussion presented in the previous sections:

From the test results slump and workability increased as percentage of rubber increased by the same water cement ratio. All the test results show that the slumps are between the designed ranges (10-30) whereas the result for mix X5 and mixX6 (31 $\mathrm{mm}$ and $37 \mathrm{~mm})$ is close to the designed range. In general, rubberized concrete mixes did not pose any difficulties in terms of finishing, casting, or placement and can be finished to the same standard as plain concrete.

The unit weight reduction was observed as percentage of rubber aggregate increased. Because of the specific gravity of the rubber aggregate is lower than that of coarse aggregates, this leads to the reduction of unit weight. Rubber aggregate is lighter than around two and half times of coarse aggregate, it was expected that the mass density of the mix would be suggestively reduced. Rubberized concrete can be used in the production of concrete floor tile which used for sidewalk or the areas which there is no heavy loads, thus the rubberized concrete could give a feasible alternative to the normal weight concrete.

The test results show that the addition of rubber aggregate resulted in a substantial reduction in concrete compressive strength compared with the control concrete. As observed from the test results there was a reduction of strength as percentage of rubber increased. The reason for the compressive strength reductions could be attributed both to a reduction of the quantity of the solid load carrying material and to the lack of adhesion at the surfaces of the rubber aggregate. Soft rubber particles behave as voids in the concrete matrix. Therefore, rubbers aggregates tend to behave like weak inclusions or voids in the concrete, resulting in a reduction in compressive strength. It is well known that the presence of voids in concrete greatly reduces its strength.

Also like compressive strength there was a reduction of tensile strength recorded with increasing rubber aggregate 
content. Because of the bond between cement paste and rubber tire particles is poor.

Increased flexural strength was observed by replacing the amount of rubber with coarse aggregate up to 10 percent used. But when the percentage of rubber increased more than 10 percent flexural strength reduction were observed. The reduction indicates that improvements in flexural strength are limited to relatively small rubber aggregate contents. It can be concluded that as the amount of rubber content increases, the reduction in the flexural strength also increases. The advantage of using rubber aggregates from waste tires or used tire are; reduction of the environmental threats caused by waste tires, an alternative source to aggregates and reduces bio disturbance which caused by during quarry of aggregates.

There was an advantage of increasing in flexural strength to some extent replacing coarse aggregate by $10 \%$ of rubber aggregate only. It can be concluded that as the amount of rubber content increases, by more than $10 \%$ the reduction in the flexural strength also increases.

Using rubber aggregates from waste tires has limitations, many issues. Like reduction of the environmental threats caused by waste tires, an alternative source of aggregates in concrete tile production, reduces the conservation of natural resources and reduces the disturbance of biodiversity of occurred during quarrying of aggregates.

Generally, this study shows that it is possible to use waste (used) rubber tire in concrete tile production as a partial replacement of coarse aggregates. But the percentage should be limited.

\section{References}

[1] Kumaran, S. G., Nurdin M. and Lakshmipathy M., A Review on Construction Technologies that Enable Environmental Protection: Rubberized Concrete, USA, Science Publications, 2008.

[2] Al-Akhras, Nabil M., and Mohammed M. Smadi. "Properties of tire rubber ash mortar." Cement and concrete composites 26.7 (2004): 821-826.

[3] Kaloush, K. E, George B. W. and Han Z., Properties of Crumb Rubber Concrete, Arizona: Arizona State University, 2004.

[4] Groom R. E., Hanna J. A. and Tutu O., New Products incorporating Tire Materials, Northern Ireland: Questor Centre, 2005 .

[5] Prakash P., Sharma S. C. and Murthy C. S., Study of Crumb Rubber waste in Cement stabilized soil blocks, Bangalore, 2006.

[6] Vanessa, C., Linda, G., Ase H., Joanne W. And Krishna R., Use of Shredded Tires as a Lightweight Backfill Material for Retaining Structures, Chicago: University of Illinois at Chicago, 1995.

[7] Gintautas, S., Audrius G. and Benjaminas C., Deformation Properties of Concrete with Rubber Waste Additives, Lithuania: Kaunas University of Technology, 2007.
[8] Carol Carder, Rubberized concrete, Colorado: Rocky Mountain Construction, 2004.

[9] Barnet J. and Associates Ltd, Recycling and Secondary Aggregates, Dublin, 2004.

[10] Sidney Mindess, Young J. F. and David Darwin, Concrete, 2nd edition, New Jersey: Prentice hall, 2003.

[11] Emiroglu, M., Kelestemur M. H. and Yildiz S., An Investigation on ITZ Microstructure of The Concrete Containing Waste Vehicle Tire, Istanbul: Firat University, 2007.

[12] Cairns, R., Kew H. Y. and Kenny M. J., the Use of Recycled Rubber Tires in Concrete Construction, Glasgow: The Onyx Environmental Trust, 2004.

[13] Meyer, C., Concrete As a Green Building Material, New York, 2004.

[14] Naik, T. R. and Moriconi G., Environmental-friendly durable Concrete made with Recycled materials for Sustainable Concrete Construction, Milwaukee: University of Wisconsin, 2005. 85 .

[15] ASTM International Standards, http://www.astm.org/standards, 2009.

[16] The Portland Cement Association, http://www.cement.org, 2009.

[17] Wallis, M. J., Sustainable Re-use of Tires in Port, Coastal and River Engineering, Seattle: HR Wallingford, 2005.

[18] Shewaferaw Dinku, the Use of Manufactured Sand In Concrete Production: Test Results And Cost Comparison, MSc Thesis, Addis Ababa, 2006.

[19] The Rubber Manufacturers Association, http://www.rma.org, 2009.

[20] Danko, Michelle, Edgar, Cano and Jose Pena, Use of Recycled Tires as Partial Replacement of Coarse Aggregate in the Production of Concrete, Purdue University Calumet, 2006.

[21] Wikipedia the Free Encyclopedia, http://en.wikipedia.org, 2009.

[22] Stutz, John, Sara Donahue, Erica Mintzer, and Amy Cotter, Recycled Rubber Products in Landscaping Applications, Boston: Tellus Institute, 2003.

[23] Federal Negarit Gazette of the Federal Democratic Republic of Ethiopia, Solid Waste Management Proclamation, 13th year, No. 13, Addis Ababa, 2007.

[24] J. Felipe A., Jeannette Santos, the Use of Recycled Polymers and Rubbers in Concrete, Florida, 2004. 86.

[25] Hallett, Paul The Use of Post-Consumer Tires as Aggregate, London: ais, 2002.

[26] Abbott, Michael Crumb Rubber in Sport and Play, Dundee, 2001.

[27] Ling T. C. and Hasanan M. N., Properties of Crumb Rubber Concrete Paving Blocks With and without Facing Layer, Kuala lumpur, 2006.

[28] Naik T. R. and Rafat Siddique, Properties of Concrete Containing Scrap Tire rubber -an Overview, Milwaukee, 2002. 
[29] Abebe Dinku, Construction Materials Laboratory Manual, Addis Ababa University Printing Press, Addis Ababa, 2002.

[30] Yunping Xi, Yue Li, Zhaohui Xie, and Lee J. S., Utilization of Solid Wastes (Waste Glass and Rubber Particles) as Aggregates in Concrete, Colorado, 2003.

[31] U. S. Army Engineer Research and Development Center Reuse Of Concrete Materials From Building Demolition, Washington DC, 2004.

[32] Abebe Dinku, DOE Method of Mix Design Process, Addis Ababa, 2008. [Lecture, AAU, Faculty of Technology, Civil Engineering Department, 2007/2008].
[33] Kang Jingfu, Han Chuncui and Zhang Zhenli, RollerCompacted Concrete using Tire-Rubber Additive, Tianjin, 2008.

[34] Ethiopian Tire and Rubber Economy Plant P. L. C., 2009. [Brochure].

[35] Khatib, Z. K. and Bayomy, F. M., "Rubberized portland cement concrete," Journal of Materials in Civil Engineering, 1999, pp. 206-213.

[36] Mossie, 2002.

[37] Ethiopian central statics agency, 2007. 